\title{
Age-related changes of dental pulp tissue after experimental tooth movement in rats
}

Martina Von Böhl, Yijin Ren, Anne M Kuijpers-Jagtman, Piotr S Fudalej, Jaap C. Maltha

It is generally accepted that the effect of orthodontic tooth movement on the dental pulp in adolescents is reversible and that it has no long-lasting effect on pulpal physiology. However, it is not clear yet if the same conclusion is also valid for adult subjects. Thus, in two groups of rats, aged 6 and 40 weeks respectively, 3 molars, at one side of the maxilla, were moved together in a mesial direction with a standardized orthodontic appliance delivering a force of $10 \mathrm{cN}$. The contralateral side served as a control. Parasagittal histological sections were prepared after tooth movement for $1,2,4,8$, and 12 weeks. The pulp tissue was characterized for the different groups, with special emphasis on cell density, inflammatory cells, vascularity, and odontoblasts. Dimensions of dentin and the pulpal horns was determined and related with the duration of orthodontic force application and age ware evaluated. We found that neither in young nor in adult rats, force application led to long-lasting or irreversible changes in pulpal tissues. Dimensional variables showed significant age-related changes. In conclusion, orthodontic tooth movement per se has no long-lasting or irreversible effect on pulpal tissues, neither in the young nor in the adult animals. 


\section{Age-related changes of dental pulp tissue after experimental tooth movement in rats}

2

6 It is generally accepted that the effect of orthodontic tooth movement on the dental pulp in

7 adolescents is reversible and that it has no long-lasting effect on pulpal physiology.

8 However, it is not clear yet if the same conclusion is also valid for adult subjects. Thus, in two

9 groups of rats, aged 6 and 40 weeks respectively, 3 molars, at one side of the maxilla, were

Martina Von Böhl, Yijin Ren, Anne M Kuijpers-Jagtman, Piotr S Fudalej, Jaap C Maltha moved together in a mesial direction with a standardized orthodontic appliance delivering a force of $10 \mathrm{cN}$. The contralateral side served as a control. Parasagittal histological sections were prepared after tooth movement for 1, 2, 4, 8, and 12 weeks. The pulp tissue was characterized for the different groups, with special emphasis on cell density, inflammatory cells, vascularity, and odontoblasts. Dimensions of dentin and the pulpal horns was determined and related with the duration of orthodontic force application and age ware evaluated. We found that neither in young nor in adult rats, force application led to long-lasting or irreversible changes in pulpal tissues. Dimensional variables showed significant age-related changes. In conclusion, orthodontic tooth movement per se has no long-lasting or irreversible effect on pulpal tissues, neither in the young nor in the adult animals. 
20 Age-related changes of dental pulp tissue after experimental tooth movement in rats

21

M. Von Böhl, ${ }^{1}$ Y. Ren, ${ }^{2}$ A.M. Kuijpers-Jagtman, ${ }^{1} \quad$ P.S. Fudalej, ${ }^{3,4}$ J.C. Maltha, ${ }^{1}$

23

24

${ }^{1}$ Department of Orthodontics and Craniofacial Biology, Radboud University Nijmegen Medical

25 Centre, Nijmegen, The Netherlands;

2 Department of Orthodontics, University Medical Centre Groningen, Groningen, The

27 Netherlands

3 Department of Orthodontics and Dentofacial Orthopedics, University of Bern, Bern,

29 Switzerland

$30{ }^{4}$ Department of Orthodontics, Palacky University Olomouc, Olomouc, Czech Republic

Running title: Dental pulp changes

Corresponding author:

Piotr S. Fudalej

Department of Orthodontics and Dentofacial Orthopedics,

37 University of Bern

$38 \quad$ Freiburgstrasse 7

393006 Bern

40 Switzerland

41 Phone: 0041316322592

42 Email: Piotr.Fudalej@zmk.unibe.ch 


\section{Abstract}

50 It is generally accepted that the effect of orthodontic tooth movement on the dental pulp in

51 adolescents is reversible and that it has no long-lasting effect on pulpal physiology. However, it 52 is not clear yet if the same conclusion is also valid for adult subjects. Thus, in two groups of rats, 53 aged 6 and 40 weeks respectively, 3 molars, at one side of the maxilla, were moved together in a 54 mesial direction with a standardized orthodontic appliance delivering a force of $10 \mathrm{cN}$. The contralateral side served as a control. Parasagittal histological sections were prepared after tooth movement for $1,2,4,8$, and 12 weeks. The pulp tissue was characterized for the different groups, with special emphasis on cell density, inflammatory cells, vascularity, and odontoblasts. Dimensions of dentin and the pulpal horns was determined and related with the duration of orthodontic force application and age ware evaluated. We found that neither in young nor in adult rats, force application led to long-lasting or irreversible changes in pulpal tissues. movement per se has no long-lasting or irreversible effect on pulpal tissues, neither in the young nor in the adult animals.

\section{Key Words}

66

Dental pulp, orthodontics, tooth movement, ageing, wear, rats 
69

70

71

72

73

74

75

\section{Introduction}

Conflicting results have been presented on the putative adverse effects of orthodontic tooth movement on the dental pulp. Some claim permanent damage (Hargreaves et al. 2002), but others find no significant long-lasting effects (Unsterseher et al. 1987). It is well known that the application of orthodontic forces induces the release of proinflammatory cytokines in the dental pulp, leading to a temporal acute inflammation and hyperemia (Raiden et al. 1998). Part of this reaction is an upregulation of IL-1 $\alpha$, IL-1 $\beta$, IL-3, IL-6, and TNF $\alpha$ (Bletsa et al. 2006; Yamaguchi et al. 2004) and apoptosis (Perinetti et al. 2004; Perinetti et al. 2005; Shigehara et al. 2006; Yamaguchi et al. 2004).

Studies in adult rats have shown that the vascular reaction shows biphasic characteristics. An initial decrease for approximately 30 minutes is followed by a temporary increase in blood flow for the subsequent 24 to 72 hours (Santamaria et al. 2007; Santamaria et al. 2006). Others, however, reported a reversible increase in the number of blood vessels during the first three to seven days of force application (Abi-Ramia et al. 2010; Nixon et al. 1993; Shigehara et al. 2006). However, after 6 weeks the vascularity of the pulp had returned to normal, even in cases with severe root resorption (Tripuwabhrut et al. 2010). Studies on isolated human pulp cells derived from premolars extracted during orthodontic tooth movement have shown that increase in vascularity might be caused by a stimulation of angiogenesis through an upregulation of VEGF, FGF2, PDGF, and TGF $\beta$ (Derringer \& Linden, 1998; Derringer \& Linden, 2003; Derringer \& Linden, 2004) 
90 Such temporal changes in pulpal blood flow are not only found during tipping movements in

91 rats, but also during intrusion and extrusion in human adults (Barwick, 1996; Sano, 2002) and

92 adolescents \{Raiden, 1998; Ramazanzadeh, 2009; Subay, 2001).

93 Temporal vacuolization of the odontoblasts or disruption of the odontoblastic layer in the dental

94 pulp is often described in adolescent humans after intrusion or extrusion (Mostafa et al., 1991;

95 Ramazanzadeh et al., 2009; Stenvik and Mjor, 1970) and in rats and dogs during orthodontic

96 tooth movement (Abi-Ramia et al., 2010; Anstendig and Kronman, 1972) or during intrusion

97 (Abi-Ramia et al., 2010; Konno et al., 2007; Santamaria et al., 2007) . However, others reported

98 no effects in rats during tipping movement. (Abi-Ramia et al., 2010; Massaro C da et al., 2009;

99 Santamaria et al., 2007)

100 The above mentioned studies have been performed in adolescent humans or in young adult

101 animals. They suggest that pulpal reactions, evoked by orthodontic interventions are reversible

102 and have no long-lasting effect on pulpal physiology. However, an ever-growing number of adult

103 and elderly individuals seek orthodontic treatment and the question arises whether pulpal

104 reactions on orthodontic therapy change with age.

105 It is well known that canal and chamber volume is inversely proportional to age. Reparative

106 dentin resulting from restorative procedures, trauma, attrition, and recurrent caries also

107 contributes to decrease of canal and chamber size (Hargreaves \& Cohen 2011). Other age-related

108 changes in the pulp are compromised circulation and innervation, fat droplet deposition,

109 odontoblastic vacuolization, reticular atrophy, pulpal fibrosis, hyaline degeneration, mucoid

110 degeneration, and diffuse calcification (Bernick \& Nedelman 1975; Morse 1991).

111 As many of the age-related changes of the dental pulp are also described to be induced by

112 orthodontic interventions, discrimination between the two is difficult (Hargreaves \& Cohen2011; 
113 Hargreaves et al. 2002). Therefore, the present study was meant to investigate the putative

114 differences between rat pulp

115 tissue in young and adult rats and possible additional long-lasting effect of experimental tooth 
116 movement, using a standardized appliance exerting a force of constant magnitude and direction.

117 In a previous study this appliance has been shown to result in an almost bodily tooth movement.

118 The hypothesis to be tested was that pulpal effects of orthodontic tooth movement are not age-

119 dependent.

120

121 Material and Methods

122

123 Ethical permission for the study was obtained according to the guidelines of the Board for

124 Animal Experiments of the Radboud University Nijmegen.

125

126 Two groups of 30 male Wistar rats, one aged 6 weeks (150-250 g) and the other 40 weeks (400-

$127550 \mathrm{~g})$ respectively, were acclimatized for 2 weeks before the start of the experiment. They were

128 housed under normal laboratory conditions and fed powdered rat chow (Sniff, Soest, The

129 Netherlands) and water ad libitum. A standard 12-hour light-dark cycle was maintained. The age

130 of 6 weeks in rats corresponds with a circumpubertal age in humans (i.e. 12-15 years), and the

131 age of 40 weeks corresponds with adult age in humans (Sengupta 2013).

132

133 A split-mouth design was used with the experimental side randomly chosen and the contralateral

134 side as the control. Power analysis with the following assumptions: $\alpha=0.05, \beta=0.2, d=5$, and $s$

$135=3$, demonstrated that $\mathrm{N}=6$ per group (i.e. 6 experimental and 6 control sides for each time

136 point) is sufficient for the analyses with a power of 0.8 .

137

138 An orthodontic appliance was placed only on the experimental side under general anesthesia 
139 (FFM-mix $2.8 \mathrm{ml} / \mathrm{kg}$ intraperitoneally, containing fluanisone $6.8 \mathrm{mg} / \mathrm{kg}$, fentanyl $0.1 \mathrm{mg} / \mathrm{kg}$, and

140 midazolam $3.4 \mathrm{mg} / \mathrm{kg}$.) (Janssen, Beerse, Belgium). The appliance has been described

141 extensively elsewhere (Ren et al., 2004; Ren et al., 2003). In brief, a transverse hole was drilled

142 through the middle root level of the upper incisors and alveolar bone and a stainless steel ligature

143 wire was put through it. A preformed ligature wire $(\Phi 0.20 \mathrm{~mm})$ enclosing all three upper molars

144 was bonded (Clearfil SE Bond, Kuraray Europe GmbH, Dusseldorf, Germany) to the buccal side

145 of the molars. By this the three molars could be moved mesially as one unit by a Sentalloy®

146 closed coil spring (10cN, $\Phi 0.22 \mathrm{~mm}$, eyelet $\Phi 0.56 \mathrm{~mm}, \mathrm{GAC}, \mathrm{NY}, \mathrm{USA})$ that was attached to

147 the ligature through the upper incisors at one end and the ligature around the three molars at the

148 other end (Fig. 1). This appliance has two major advantages. First, the molar unit is almost

149 bodily moved related to the relative large mesiodistal dimensions of the molar block that is to be

150 moved, and second, the force per molar is comparable to normally used forces in the clinical

151 situation (Ren et al., 2004; Ren et al., 2003) . After a force application for 1, 2, 4, 8, or 12

152 weeks, 6 rats from the "young" and 6 animals of the "old" groups were killed.

Histological procedure

155 The rats received a lethal dose of anesthetic before they were killed. They were then perfused 156 with $4 \%$ paraformaldehyde solution in $0.1 \mathrm{M} \mathrm{PBS}$ at $37^{\circ} \mathrm{C}$. The maxillae were dissected and 157 immersed in $4 \%$ paraformaldehyde for 24 hours at $4^{\circ} \mathrm{C}$, then they were rinsed in $0.1 \mathrm{M}$ phosphate 158 buffered saline (PBS). After decalcification in 10\% ethylenediaminetetraacetate (EDTA) and 159 paraffin embedding, serial parasagittal $7 \mu \mathrm{m}$ sections were cut. Every 25 th section was collected 160 and stained with hematoxylin and eosin. 
162 Measurements

163 Tooth positions were measured at the control and the experimental sides as the distance between

164 the most mesial point of the first molar and the enamel cementum border of the ipsilateral incisor

165 at the gingival gingival level (I-M distance) at the following time points $0,1,2,4,8$, and 12

166 weeks. The experimental tooth movement was calculated as the changes in the difference

167 between the I-M distances at the experimental and the conrol side. By this method, possible

168 confounding factors as anchorage loss from the incisors and physiological distal drift of the

169 molars is compensated for.

170

171 From each rat three sections were selected from both the experimental and the control side, in

172 which at least one root was completely present including the pulp chamber and the apical

173 foramen. From these sections, the histological features of the dental pulp were described, with

174 special emphasis on odontoblastic layer, blood vessels, cell density, and inflammatory cells in

175 the pulp chamber.

176

177 To describe the dimensional changes in tooth morphology during the experimental period in the

178 young as well as in the old group, the following parameters were measured in arbitrary units

179 (AU) as illustrated in Figure 2: distal and mesial crown height as the distance from the occlusal

180 surface to the cementoenamel junction (CEJ) $(1,2)$, dentin thickness at the cusps $(3,4,5)$, dentin

181 thickness in the fissures $(6,7)$, predentin thickness at the cusps $(8,9,10)$, predentin thickness in

182 the fissures $(11,12)$, and the height of the pulpal horns, related to a line through the border

183 between dentin and cementum in the fissures $(13,14,15)$. Prior to statistical analysis, for each

184 individual side, the means were calculated for the variables crown height, dentin height cusp, 
185 dentin height fissure, predentin height cusp, predentin height fissure, and height pulpal horn.

186

\section{Statistical analysis}

188 The differences between the amount of tooth movement between the young and the old animals was analyzed by Students $t$ tests. The data of the dimensional measurements on the molars from the two age groups were initially analyzed by a two-way ANOVA on the raw data of all variables, with the group (experimental or control), and the duration of force application $(1,2,4,8$, or 12 weeks) as independent factors. As this analysis showed no significant group effect for any of the variables, the data from the experimental and the control sides were pooled. Subsequently, the time effects were analyzed by one-way ANOVA on all dimensional variables in both age groups separately with the experimental period as independent variable.

A separate one-way ANOVA was performed after the data from both age groups were combined to study the long term changes in these parameters with the real age of the animals as independent factor. A linear regression analysis was performed and the explained variance was calculated for all parameters in the two age groups and in the combined age group.

\section{Results}

\section{Experimental tooth movement}

Throughout the whole experimental period the teeth in the young animals had moved significantly more than in the old animals. The teeth showed initially a fast movement of $1.05 \pm$ 
208 slowed down to about $0.05 \mathrm{~mm} / \mathrm{w}$ for the young and $0.02 \mathrm{~mm} / \mathrm{w}$ for the old animals at the end of

209 the experimental period. The total tooth movement over the experimental period of 12 weeks

210 was $2.69 \pm 0.62 \mathrm{~mm}$ for the young and $1.23 \pm 0.56 \mathrm{~mm}$ for the old animals, and the tooth

211 movement curves can best be described by logarithmic equations, showing an R2 of 0.996 and

2120.965 for the young and the old group respectively.

213

214 Histological dental pulp tissue survey

\section{Control side in young rats}

217 No histological differences were encountered between animals, which were for a short (1-2

218 weeks) or long period (8-12 weeks) in the experiment. The pulps in the control teeth showed 219 only very few inflammatory cells and small blood vessels (Fig. 3A). The odontoblastic layer and cementum surface showed an irregular morphology. At the roof of the pulp chamber and in the pulpal horns just a thin predentine layer was seen (Fig. 3A). The tips of the cusps showed very little or no wear (Fig.3C).

\section{Experimental side in young rats}

Again, no histological differences were encountered between animals, which were for a short (1-

2 weeks) or a long period (8-12 weeks) in the experiment.

The pulp of the experimental teeth showed a lower cell density than the controls, and inflammatory cells were scarce. The number of blood vessels was increased compared to the controls and in general their diameter was larger (Fig. 3B). The odontoblastic layer and cementum surface were irregular. The predentin layer at the top of the pulp chamber appeared to 
231 be slightly thicker than in the controls (Fig. 3B). Similar to the control animals, the tips of the

232 cusps showed very little or no wear.

233

234 Control side in old rats

235 No substantial histological differences were found between animals that stayed for a short (1-2

236 weeks) or long period (8-12 weeks) in the experiment. In the control teeth from the old group,

237 the pulpal cell density was less than in the young animals. Only few inflammatory cells were

238 present. A limited number of small blood vessels were present throughout the pulp (Fig. 3D)

239 The odontoblastic layer and predentin were well organized. At the top of the pulp chamber the

240 predentin layer tended to be somewhat thicker than in the young animals (Fig. 3D). The tips of

241 the cusps showed severe wear (Fig. 3F). 


\section{Experimental side in old rats}

244 Again, no substantial histological differences were found between animals that stayed for a short 245 (1-2 weeks) or long period (8-12 weeks) in the experiment. The number of inflammatory cells in

246 the dental pulp was larger than in the control teeth. The number of blood vessels was larger and

247 they showed a larger diameter compared to the controls (Fig. 3E). The odontoblastic cell layer 248 and the predentin surface were organized in a regular way. The predentin layer in the pulpal

249 horns and the roof of the pulp chamber was thicker than in the young animals and similar to the 250 control animals in the old group (Fig. 3E). The tips of the cusps showed severe wear, similar to 251 the controls. The amount of wear increased during the experimental period.

\section{Dimensional parameters}

254 Figs. 3C and 3F illustrate the general morphology of the first molars in the young and the old 255 group.

256 Two-way ANOVA with the group (experimental or control), and duration of force application $257(1,2,4,8$, or 12 weeks $)$ as independent factors showed no significant group effect for any of the 258 variables. Therefore, the data from the experimental and the control groups were pooled (Table 259 1). 
260 The one-way ANOVA for none of the mean variables in the young group showed any significant

261 time effect, low correlation coefficients $(\mathrm{R} \leq 0.2)$ and a very small explained variance $\left(\mathrm{R}^{2} \leq 0.05\right)$

262 (Table 2). In the old group only the mean crown height showed a significant decrease, and the

263 mean thickness of the dentin in the cusps a significant increase over time. The explained variance

264 (R2) was 0.42 and 0.67 respectively (Table 2).

265

266 The ANOVA of the combined data with the real age of the animals as independent factor showed

267 significant age effects for all variables, except for the mean dentin thickness in the fissure $(\mathrm{p}=$

268 0.308), and the mean predentin thickness in the cups $(\mathrm{p}=0.641)$ (Table 2$)$. The mean crown

269 height decreased significantly with the real age (Fig. 4A), as did the thickness of the dentin layer

270 in cusps (Fig. 4B). Both variables showed a high explained variance (R2) of 0.745 and 0.506

271 respectively. Both other variables, showing a significant time dependency show far smaller

272 explained variances, namely 0.247 for the mean predentin thickness in the fissure (Fig. 4C) and

2730.172 for the mean height of the pulpal horn (Fig. 4D).

275 Post-hoc analysis showed in general, a significant larger crown height in the young than in the old group. The thickness of the dentin layer on all cusps is significantly larger in the young group than in the old one, the predentin layer in the fissures is significantly thinner in the young group than in the old one, and finally the height of the pulpal horn in the young group is larger than in the old group ( $\mathrm{p}$-values for all these variables $<0.05$ ).

\section{Discussion}

282 In many textbooks it is suggested that changes in the pulp tissue due to the aging process, such as 
283 reduction of the number and volume of the blood vessels or an increase in collagen fibers are 284 diverse and irreversible (Hargreaves \& Cohen 2011; Hargreaves et al. 2002). However, very

285 little information is available about the additional influence of orthodontic force application on

286 the aged pulp tissue. Therefore, the aim of the present study was to investigate the effect of 287 experimental orthodontic tooth movement on young or aged dental pulp tissue. The rat was 288 chosen as experimental animal and an appliance was used that has been developed earlier (Ren et al. 2004; Ren et al. 2003). This appliance has been proven to be stable and simple and is able to deliver a continuous and constant force as low as $10 \mathrm{cN}$ on all three molars together. The total tooth movement over the 12 weeks experimental period was significantly more for the young than for the old animals. This force is comparable with a force of $170 \mathrm{cN}$ on a human molar and thus more comparable to the clinical situation, than in most of the rat models(Abi-Ramia et al. 2010; Bletsa et al. 2006; Grunheid et al. 2007; Santamaria et al. 2007; Shigehara et al. 2006; Tripuwabhrut et al. 2010) that use forces over $20 \mathrm{cN}$ on only one molar (comparable to approx. $1000 \mathrm{cN}$ on human molar) $\{$ Ren, $2004 \# 52\}$. This might explain that in the present study only minor effects of orthodontic force application on pulpal tissues became apparent.

Another reason that no clear effects on pulpal tissues have been found in the present study might be that our appliance induced an almost bodily movement of the molar block (Ren et al, 2004; Ren et al, 2003), while others used tipping movements of the first molar only (Abi-Ramia et al. 2010; Bletsa et al. 2006; Grunheid et al. 2007; Santamaria et al. 2007; Shigehara et al. 2006; Tripuwabhrut et al. 2010), intrusion (Barwick \& Ramsay 1996; Ikawa et al. 2001; Konno et al. 2007; Raiden et al. 1998; Ramazanzadeh et al. 2009; Stenvik 1971; Veberiene et al. 2009), or extrusion (Ramazanzadeh et al. 2009; Stenvik 1971; Subay et al. 2001). 
306 The only pulpal change that was consistently found was a small increase in the vascularity in

307 both the young and the old tooth movement group. This is in agreement with several other

308 authors (Nixon et al. 1993; Raiden et al. 1998; Sano et al. 2002; Shigehara et al. 2006; Wong et

309 al. 1999). A drawback of the chosen measurement protocol in which the first histological

310 evaluation is performed after one week is that short-lasting changes in the pulpal tissue, as

311 described in the literature will be missed (Barwick \& Ramsay 1996; Bletsa et al. 2006; Brodin et

312 al. 1996; Ikawa et al. 2001; Nixon et al. 1993; Santamaria et al. 2007; Santamaria et al. 2006).

313 However, this is not a serious problem as short-lasting pulpal changes are of less clinical

314 importance than persisting ones.

316 The finding that the dimensional variables in the young animals did not show any significant

317 time effect can be explained in two ways. The first is that they do not change at all over the 12-

318 week period; the other is that the changes are very slow and variable. As the changes in the

319 dimensional variables are all related to occlusal wear of the dental tissues, it seems reasonable to

320 suppose that their changes over time will be very slow as long as the crown is covered by

321 enamel. During the 12-week experimental period in the old animals, a significant decrease with a

322 high explained variance is found for the mean crown height and the mean thickness of the dentin

323 in the cusps. This suggests a faster wear in the absence of occlusal enamel, which was probably

324 worn by normal physiological processes before the animals were included in the study at an age

325 of 40 weeks. As a consequence, secondary dentin deposition in the pulpal horns was stimulated,

326 leading to a significant increase in its thickness, a decrease in the heights of the pulpal horns, and

327 a decrease in the volume of the pulp chamber. The analysis of the combined data from the young

328 and the old animals points in the same direction. 


\section{Conclusion}

331 In conclusion, it can be stated that the application of a light force for orthodontic tooth

332 movement in young nor adult rats did lead to long-lasting or irreversible changes in pulpal 
333 tissues, except for a tendency towards a higher vascularity. The most apparent changes are in the

334 dimensional variables, but these are caused by occlusal wear and secondary dentin formation,

335 and not by the orthodontic tooth movement. However, extrapolating this experimental data from

336 an animal study in rats to human outcome is difficult and it is not surprising that severe wear as

337 seen in rodents, is seldom encountered in adult orthodontic patients. Therefore these findings

338 have only very limited clinical implications.

339

340 Funding

341 None

342

343 Competing interests

344 All authors declare there are no competing interests.

References

Abi-Ramia LB, Stuani AS, Stuani AS, Stuani MB, and Mendes Ade M. 2010. Effects of lowlevel laser therapy and orthodontic tooth movement on dental pulps in rats. Angle Orthod 80:116-122.

Barwick PJ, and Ramsay DS. 1996. Effect of brief intrusive force on human pulpal blood flow. Am J Orthod Dentofacial Orthop 110:273-279.

Bernick S, and Nedelman C. 1975. Effect of aging on the human pulp. J Endod 1:88-94. expression during the early phases of orthodontic tooth movement in rats. Eur J Oral Sci 356 114:423-429.

357 Brodin P, Linge L, and Aars H. 1996. Instant assessment of pulpal blood flow after orthodontic 358 force application. J Orofac Orthop 57:306-309.

359 Derringer KA, and Linden RW. 1998. Enhanced angiogenesis induced by diffusible angiogenic 
360 growth factors released from human dental pulp explants of orthodontically moved teeth. Eur J 361 Orthod 20:357-367.

362 Derringer KA, and Linden RW. 2003. Angiogenic growth factors released in human dental pulp 363 following orthodontic force. Arch Oral Biol 48:285-291.

364 Derringer KA, and Linden RW. 2004. Vascular endothelial growth factor, fibroblast growth 365 factor 2, platelet derived growth factor and transforming growth factor beta released in human 366 dental pulp following orthodontic force. Arch Oral Biol 49:631-641.

367 Grunheid T, Morbach BA, and Zentner A. 2007. Pulpal cellular reactions to experimental tooth movement in rats. Oral Surg Oral Med Oral Pathol Oral Radiol Endod 104:434-441.

369 Hargreaves KM, and Cohen S. 2011. Cohen's Pathways to the Pulp. St Louis: Mosby. Hargreaves KM, Goodis HE, and Seltzer S. 2002. Seltzer and Bender's Dental Pulp. Chicago:

371 Quintessence Pub Co.

372 Ikawa M, Fujiwara M, Horiuchi H, and Shimauchi H. 2001. The effect of short-term tooth intrusion on human pulpal blood flow measured by laser Doppler flowmetry. Arch Oral Biol 46:781-787.

Konno Y, Daimaruya T, Iikubo M, Kanzaki R, Takahashi I, Sugawara J, and Sasano T. 2007. Morphologic and hemodynamic analysis of dental pulp in dogs after molar intrusion with the skeletal anchorage system. Am J Orthod Dentofacial Orthop 132:199-207. Morse DR. 1991. Age-related changes of the dental pulp complex and their relationship to systemic aging. Oral Surg Oral Med Oral Pathol 72:721-745.

Nixon CE, Saviano JA, King GJ, and Keeling SD. 1993. Histomorphometric study of dental pulp during orthodontic tooth movement. J Endod 19:13-16.

Perinetti G, Varvara G, Festa F, and Esposito P. 2004. Aspartate aminotransferase activity in pulp of orthodontically treated teeth. Am J Orthod Dentofacial Orthop 125:88-92.

Perinetti G, Varvara G, Salini L, and Tete S. 2005. Alkaline phosphatase activity in dental pulp of orthodontically treated teeth. Am J Orthod Dentofacial Orthop 128:492-496. response to intrusive orthodontic forces. Acta Odontol Latinoam 11:49-54. MT. 2009. Histological changes in human dental pulp following application of intrusive and extrusive orthodontic forces. J Oral Sci 51:109-115.

391 Ren Y, Maltha JC, and Kuijpers-Jagtman AM. 2004. The rat as a model for orthodontic tooth movement--a critical review and a proposed solution. Eur J Orthod 26:483-490.

393 Ren Y, Maltha JC, Van 't Hof MA, and Kuijpers-Jagtman AM. 2003. Age effect on orthodontic 394 tooth movement in rats. J Dent Res 82:38-42. 
395 Sano Y, Ikawa M, Sugawara J, Horiuchi H, and Mitani H. 2002. The effect of continuous 396 intrusive force on human pulpal blood flow. Eur J Orthod 24:159-166.

397 Santamaria M, Jr., Milagres D, Iyomasa MM, Stuani MB, and Ruellas AC. 2007. Initial pulp

398 changes during orthodontic movement: histomorphological evaluation. Braz Dent J 18:34-39. 
399 Santamaria M, Jr., Milagres D, Stuani AS, Stuani MB, and Ruellas AC. 2006. Initial changes in 400 pulpal microvasculature during orthodontic tooth movement: a stereological study. Eur J Orthod 401 28:217-220.

402 Sengupta P. 2013. The Laboratory rat: relating its age with human's. International Journal of 403 Preventive Medicine 4:624-30. Shigehara S, Matsuzaka K, and Inoue T. 2006.

404 Morphohistological change and expression of HSP70, osteopontin and osteocalcin mRNAs in rat 405 dental pulp cells with orthodontic tooth movement. Bull Tokyo Dent Coll 47:117-124.

406 Stenvik A. 1971. The effect of extrusive orthodontic forces on human pulp and dentin. Scand J 407 Dent Res 79:430-435.

408 Stenvik A, and Mjor IA. 1971. The effect of experimental tooth intrusion on pulp and dentine. 409 Oral Surg Oral Med Oral Pathol 32:639-648.

410 Subay RK, Kaya H, Tarim B, Subay A, and Cox CF. 2001. Response of human pulpal tissue to 411 orthodontic extrusive applications. J Endod 27:508-511.

412 Tripuwabhrut P, Brudvik P, Fristad I, and Rethnam S. 2010. Experimental orthodontic tooth 413 movement and extensive root resorption: periodontal and pulpal changes. Eur J Oral Sci 414 118:596-603.

415 Unsterseher RE, Nieberg LG, Weimer AD, and Dyer JK. 1987. The response of human pulpal 416 tissue after orthodontic force application. Am J Orthod Dentofacial Orthop 92:220-224.

417 Veberiene R, Smailiene D, Danielyte J, Toleikis A, Dagys A, and Machiulskiene V. 2009.

418 Effects of intrusive force on selected determinants of pulp vitality. Angle Orthodontist 79:11144191118.

420 Wong VS, Freer TJ, Joseph BK, and Daley TJ. 1999. Tooth movement and vascularity of the 421 dental pulp: a pilot study. Aust Orthod J 15:246-250.

422 Yamaguchi M, Kojima T, Kanekawa M, Aihara N, Nogimura A, and Kasai K. 2004.

423 Neuropeptides stimulate production of interleukin-1 beta, interleukin-6, and tumor necrosis

424 factor-alpha in human dental pulp cells. Inflammation Research 53:199-204.

425

426

427

428

429

430 


\section{FIGURE CAPTIONS}

435

Figure 1. Schematic drawing of the orthodontic appliance. The Sentalloy spring delivers a continuous force of $10 \mathrm{cN}$ on all three molars together

438

Figure 2. Schematic drawing of a parasagittal section of a rat molar. The measured parameters are indicated. For explanation see text.

Figure 3. A and B: high power pictures of the coronal pulp tissue of the control and experimental animals from the young group; D and E: high power pictures of the coronal pulp tissue of the control and experimental animals from the old group. $\mathrm{C}$ and $\mathrm{F}$ : low power pictures of rat molars of the young and old animals respectively. The most clear difference between the control and the experimental pulpal tissue is that the latter show some more and wider blood vessels. The most prominent difference between the young and the old animals is that in the latter, the odontoblasts are more well- organized and active, and the predentin layer is more pronounced. The low power pictures clearly show the dramatic difference in wear between the young and the old animals. All sections H \& E staining. 
454 Figure 4. Scatter plots of the combined measurement data from the animals from the young and 455 the old group. Linear regression s lines and $95 \% \mathrm{CI}$ are given. 


\section{Figure 1 (on next page)}

\section{Figure 1}

Schematic drawing of the orthodontic appliance. The Sentalloy spring delivers a continuous force of $10 \mathrm{cN}$ on all three molars together 


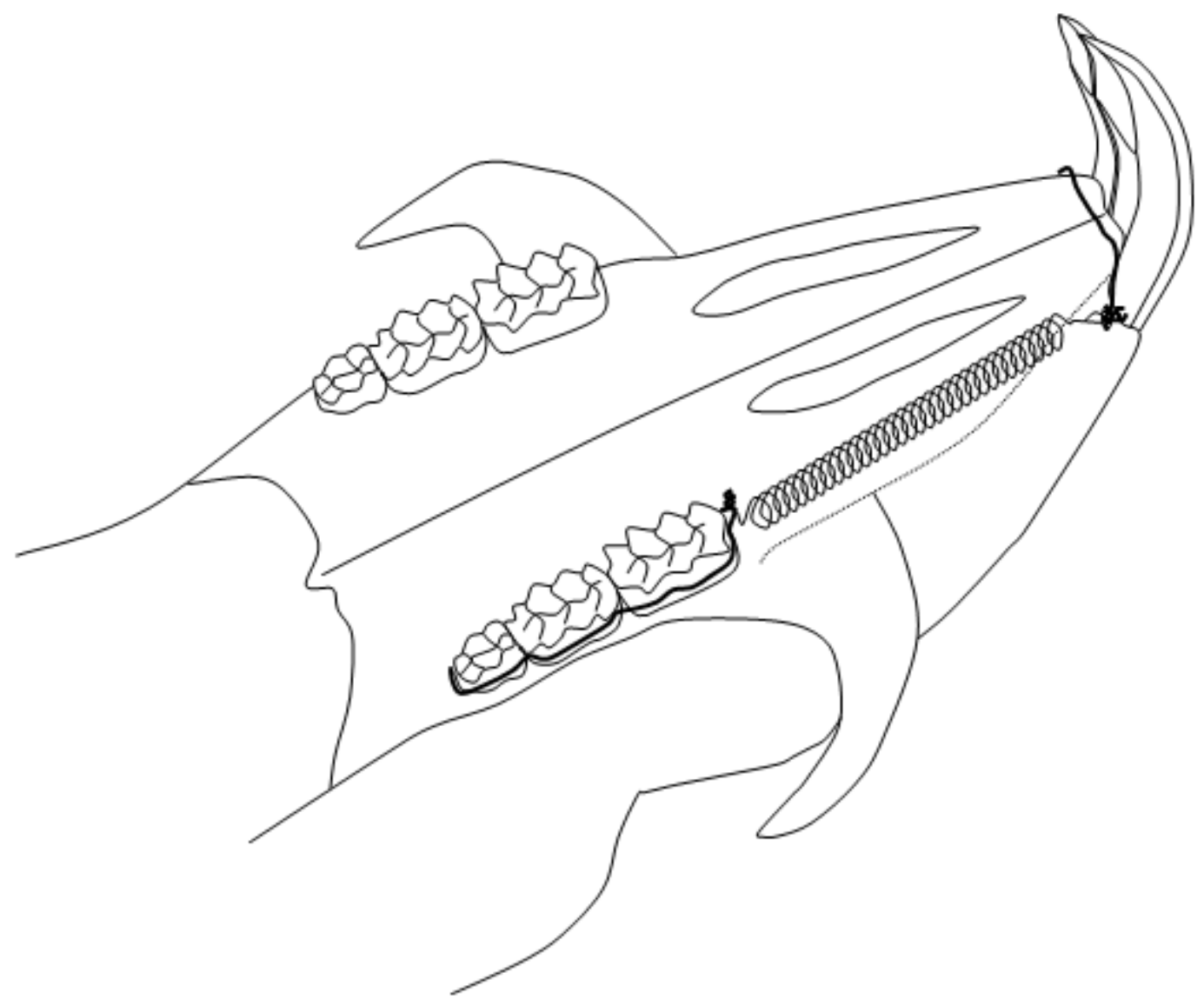




\section{Figure 2 (on next page)}

Figure 2

Schematic drawing of a parasagittal section of a rat molar. The measured parameters are indicated. For explanation see text. 


\section{PeerJ}

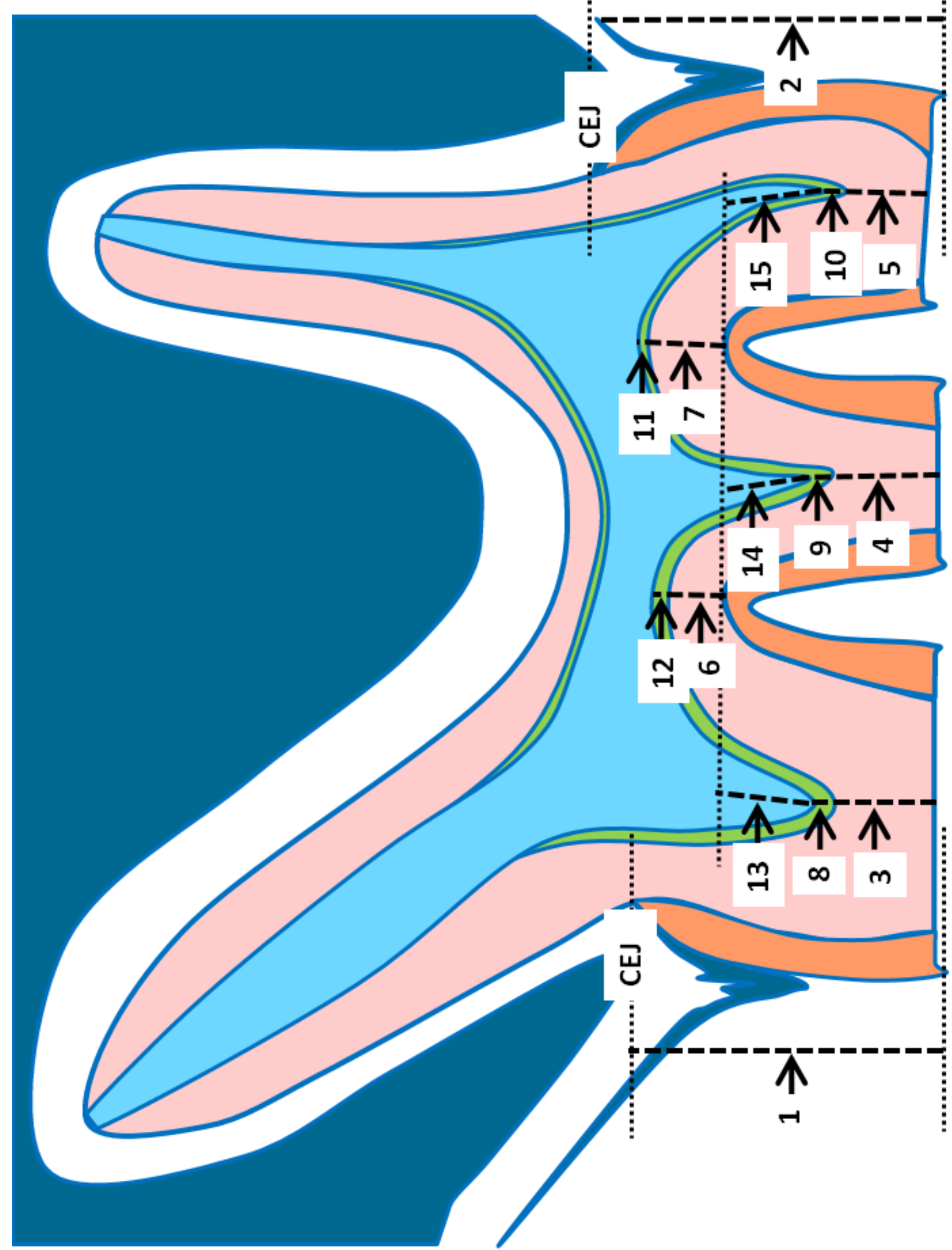


Figure 3 (on next page)

Histological sections of young $(A, B, C)$ and old rats $(D, E, F)$ 
PeerJ

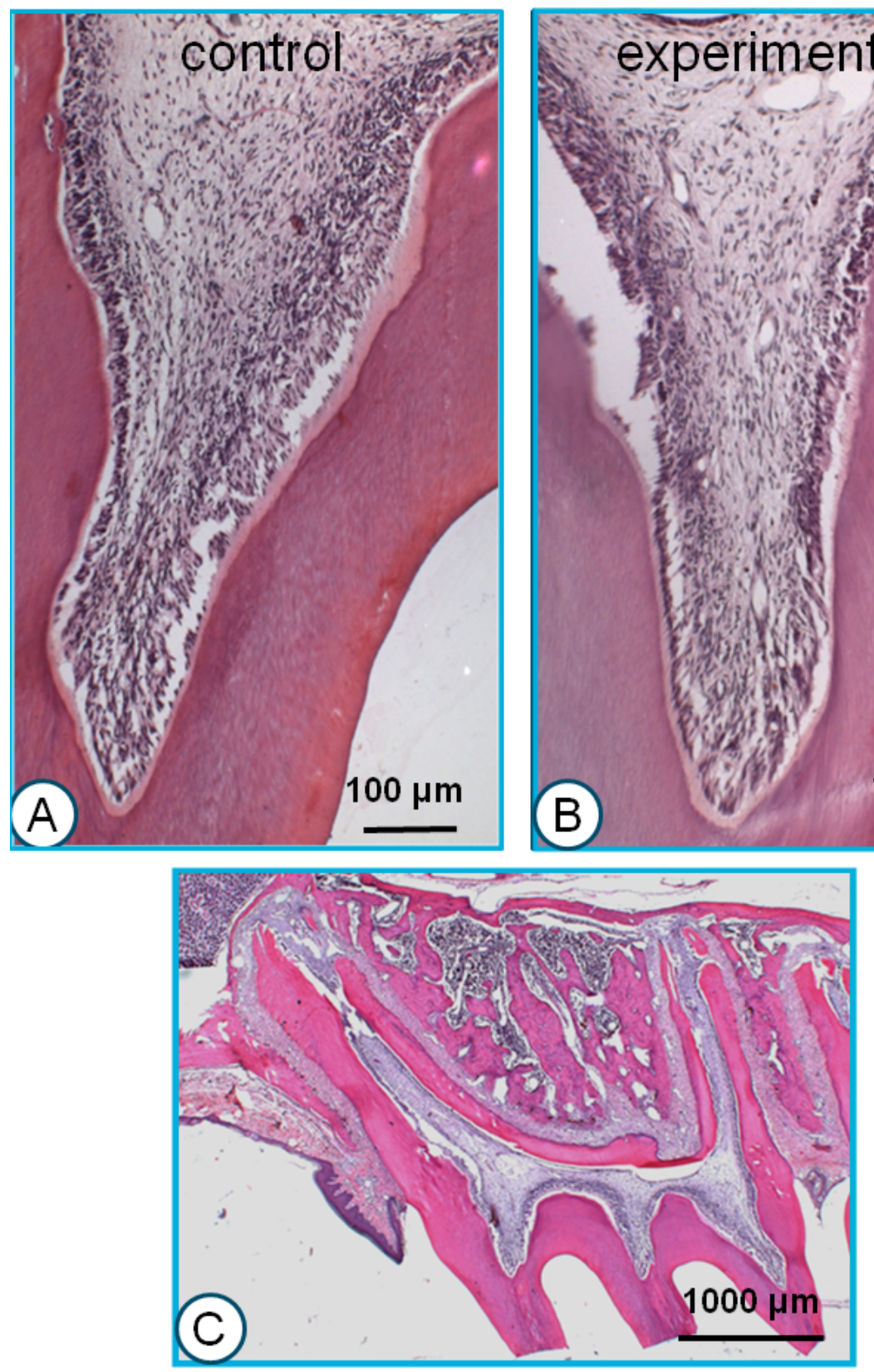

Manuscript to be reviewed
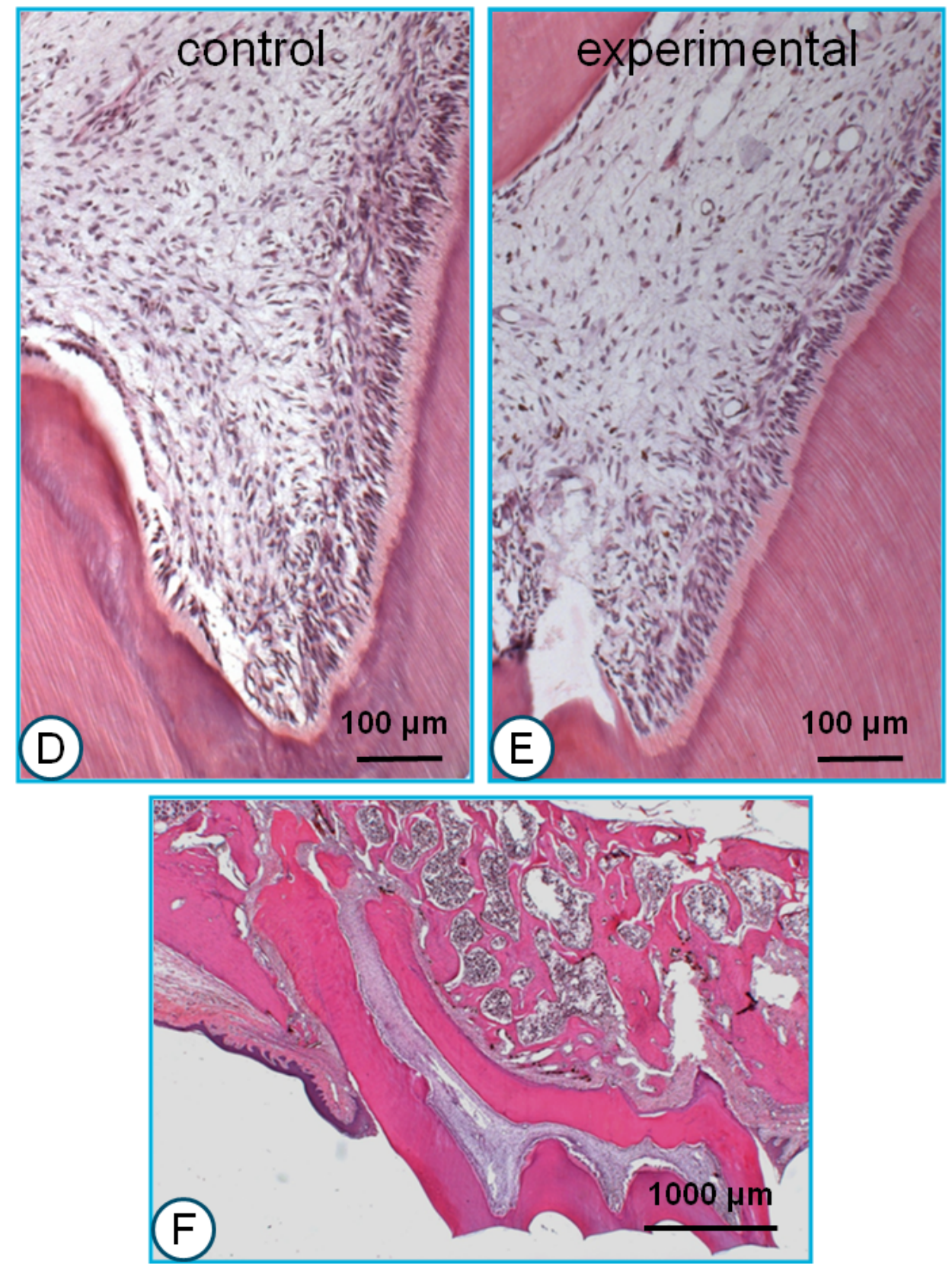


\section{Figure 4 (on next page)}

\section{Figure 4}

Scatter plots of the combined measurement data from the animals from the young and the old group. Linear regression s lines and $95 \% \mathrm{Cl}$ are given. 

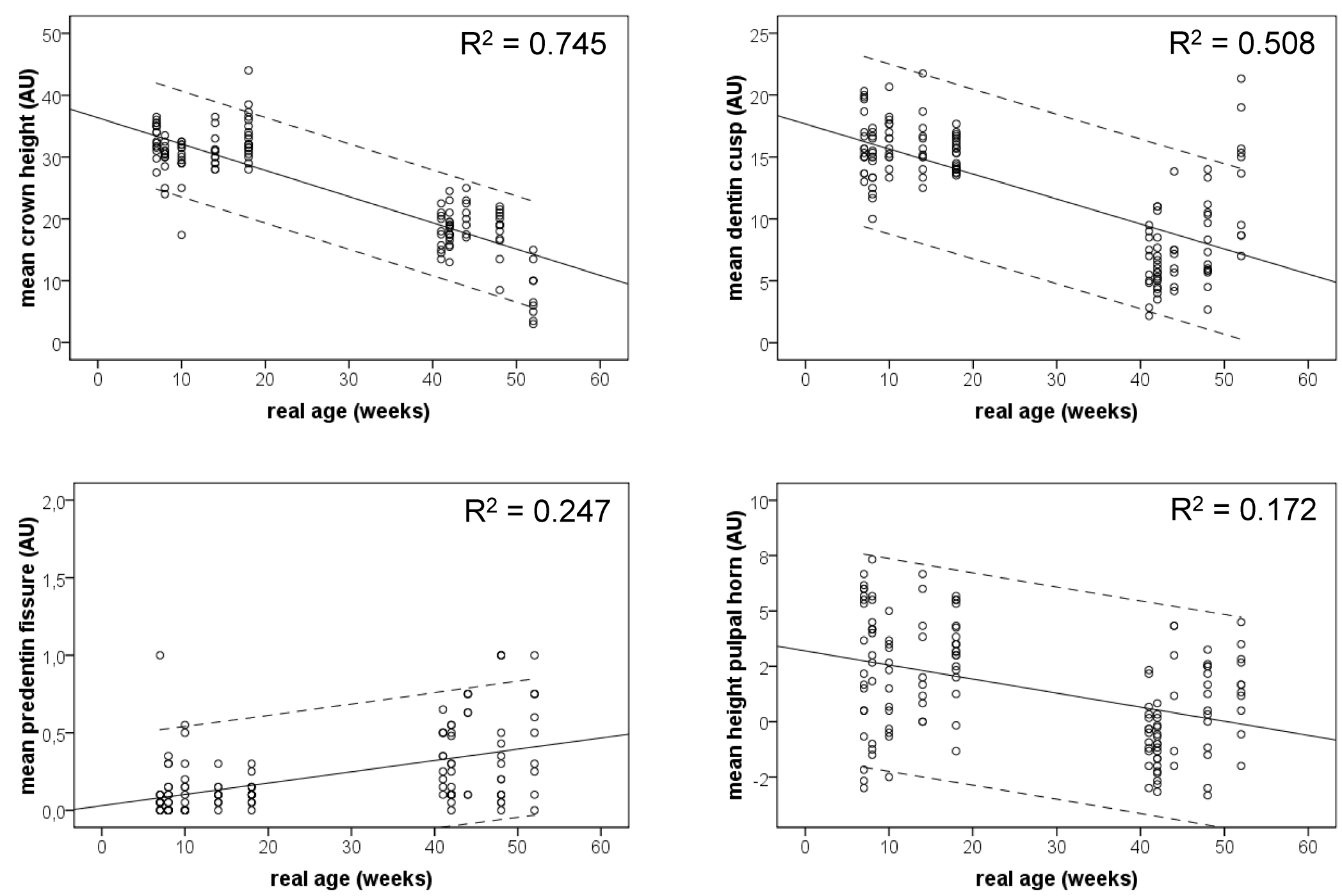


\section{Table $\mathbf{1}$ (on next page)}

Means and standard deviations (sd) for the combined data of the dimensional parameters in the young and the adult group 
1 Table 1. Means and standard deviations (sd) for the combined data of the dimensional

2 parameters in the young and the adult groups

3

4

Young group

\begin{tabular}{|c|c|c|c|c|c|c|c|c|c|c|c|c|}
\hline \multirow[t]{3}{*}{ Age (weeks) } & \multirow{2}{*}{\multicolumn{2}{|c|}{$\begin{array}{l}\text { Crown } \\
\text { Height }\end{array}$}} & \multicolumn{4}{|c|}{ Dentin } & \multicolumn{4}{|c|}{ Predentin } & \multicolumn{2}{|c|}{ Pulpal horn } \\
\hline & & & Cusp & & Fissur & & Cusp & & Fissur & & Heigh & \\
\hline & mean & $\mathrm{sd}$ & mean & $\mathrm{sd}$ & mean & $\mathrm{sd}$ & mean & $\mathrm{sd}$ & mean & $\mathrm{sd}$ & mean & $\mathrm{sd}$ \\
\hline 7 & 33.3 & 2.5 & 16.5 & 2.5 & 12.4 & 1.9 & 0.8 & 0.2 & 0.1 & 0.2 & 2.5 & 3.4 \\
\hline 8 & 30.0 & 2.5 & 14.4 & 2.2 & 13.1 & 2.2 & 0.8 & 0.3 & 0.1 & 0.1 & 3.1 & 2.7 \\
\hline 10 & 29.4 & 4.0 & 16.5 & 1.9 & 13.3 & 2.4 & 1.0 & 0.3 & 0.1 & 0.2 & 1.5 & 2.2 \\
\hline 14 & 31.0 & 2.7 & 16.0 & 2.5 & 14.3 & 2.6 & 1.0 & 0.1 & 0.1 & 0.1 & 2.7 & 2.4 \\
\hline 18 & 33.4 & 3.7 & 15.2 & 1.3 & 14.7 & 2.6 & 0.8 & 0.2 & 0.1 & 0.1 & 3.2 & 1.8 \\
\hline
\end{tabular}


5 Table 1. Means and sd for the combined data of the dimensional parameters in the young and the

6 adult groups - continued

7

8

9

\begin{tabular}{|c|c|c|c|c|c|c|c|c|c|c|c|c|}
\hline \multicolumn{13}{|c|}{ Old group } \\
\hline \multirow[t]{3}{*}{$\begin{array}{l}\text { Age } \\
\text { (weeks) }\end{array}$} & \multicolumn{2}{|c|}{ Crown } & \multicolumn{4}{|c|}{ Dentin } & \multicolumn{4}{|c|}{ Predentin } & \multirow{2}{*}{\multicolumn{2}{|c|}{$\begin{array}{l}\text { Pulpal } \\
\text { horn } \\
\text { Height }\end{array}$}} \\
\hline & \multicolumn{2}{|c|}{ Height } & \multicolumn{2}{|c|}{ Cusp } & \multicolumn{2}{|c|}{ Fissure } & \multicolumn{2}{|l|}{ Cusp } & \multicolumn{2}{|c|}{ Fissure } & & \\
\hline & mean & $\mathrm{sd}$ & mean & sd & mean & sd & mean & $\mathrm{sd}$ & mean & $\mathrm{sd}$ & mean & $\mathrm{sd}$ \\
\hline 41 & 17.8 & 3.1 & 6.2 & 2.5 & 14.3 & 0.8 & 0.9 & 0.2 & 0.4 & 0.2 & -0.3 & 1.5 \\
\hline 42 & 18.4 & 2.7 & 6.6 & 2.4 & 15.2 & 1.1 & 0.8 & 0.3 & 0.2 & 0.2 & -1.2 & 1.1 \\
\hline 44 & 20.6 & 2.8 & 7.0 & 3.0 & 10.8 & 2.8 & 0.7 & 0.1 & 0.5 & 0.3 & 1.6 & 2.8 \\
\hline 48 & 18.2 & 3.4 & 8.1 & 3.3 & 10.4 & 4.4 & 0.8 & 0.2 & 0.4 & 0.4 & 0.6 & 2.1 \\
\hline 52 & 8.3 & 4.1 & 13.4 & 4.8 & 14.1 & 2.0 & 1.1 & 0.4 & 0.5 & 0.3 & 1.6 & 1.8 \\
\hline
\end{tabular}




\section{Table 2 (on next page)}

Statistical analysis of the effect of experimental period (in the young and the old group) and real age (in the combined data) for the dimensional measurements. 
1 Table 2. Statistical analysis of the effect of experimental period (in the young and the old group)

2 and real age (in the combined data) for the dimensional measurements.

3

4

\begin{tabular}{|c|c|c|c|c|c|c|c|c|c|}
\hline \multirow{3}{*}{ variable } & \multicolumn{3}{|l|}{ Young } & \multicolumn{3}{|l|}{ Old } & \multicolumn{3}{|c|}{ Combined } \\
\hline & \multirow{2}{*}{$\frac{\text { ANOV }}{p \text {-value }}$} & \multicolumn{2}{|l|}{ Linear } & \multirow{2}{*}{$\frac{\text { ANOV }}{p \text {-value }}$} & \multicolumn{2}{|l|}{ Linear } & \multirow{2}{*}{$\frac{\text { ANOV }}{\text { p-value }}$} & \multicolumn{2}{|l|}{ Linear } \\
\hline & & CorrCoe & R2 & & CorrCoe & R2 & & CorrCoe & $\mathrm{R} 2$ \\
\hline Mean & & & & & & & & & \\
\hline Height & & & & & & & & & \\
\hline Mean & & & & & & & & & \\
\hline Cusp & 0.618 & 0.103 & 0.0 & 0.000 & 0.817 & 0.6 & 0.000 & 0.738 & 0.5 \\
\hline Mean & & & & & & & & & \\
\hline Fissure & 0.300 & 0.212 & 0.0 & 0.056 & 0.424 & 0.1 & 0.308 & 0.092 & 0.0 \\
\hline Mean & & & & & & & & & \\
\hline Predenti & 0.762 & 0.062 & 0.0 & 0.910 & 0.026 & 0.0 & 0.641 & 0.042 & 0.0 \\
\hline Mean & & & & & & & & & \\
\hline Predenti & 0.787 & 0.056 & 0.0 & 0.646 & 0.107 & 0.0 & 0.000 & 0.504 & 0.2 \\
\hline Mean & & & & & & & & & \\
\hline
\end{tabular}

5

6 CorrCoef, correlation coefficient

7 